trast agents, but this change must also have a profound effect on the design and manufacture of radiographic equipment, which could well be revolutionary. Many more image intensifiers will be required; lower voltage transformers, small focal spot-sized tubes, $105 \mathrm{~mm}$ roll film and cameras will be needed in large quantities; and automatic processing units will be a fraction of their present size. What if, in the future, there is no radiograph at all, only a "floppy disc" and a television monitor? What kind of organization will then be required to obtain and view the barium meal examination of a patient immediately before a gastrectomy? It may well be that a central console will be linked with multiple television outlets to wards, theatres, and the outpatient departments, and electronic imaging will have replaced the radiograph.

If this sounds too much like science fiction, it is worth remembering that the refinements of electronic imaging were developed to meet the needs of space travel.

${ }^{1}$ Sternglass, E. J., Sashin, D., and Heinz, E. R., Current Concepts in Radio$\log y(11)$ - Electronic Imaging in Diagnostic Radıology. St. Louis, C.V. Mosby, 1975.

2 Baum, W.A., in Astronomical Techniques, ed. A. Hiltner. Chicago, University of Chicago Press, 1962.

${ }^{3}$ Sashin, D., et al., Radiology, 1973, 106, 551.

\section{Volunteers and the Aftermath of Stroke}

About 100000 people are alive in Britain today who have been seriously disabled by stroke, often at the height of their powers with long years before them. Rehabilitation can help them greatly, but eventually they have to be discharged. For some a return to work or to an active role at home is possible, but many whose powers of communication are seriously impaired return only to frustration and despair. These patients are by no means neglected everywhere-day centres and stroke clubs provide a valuable service-but at best these facilities rarely allow for more than a weekly attendance. Until now there has been no scheme designed to fill the long gaps in each patient's life and to encourage further progress. The immediate family have had to try to cope with a situation which has almost always been beyond them.

In a thought-provoking article at p. 633 Miss V. E. Griffith describes a scheme in which volunteers (with the approval of the family doctors, consultants, and speech therapists) made regular visits to stroke patients suffering from dysphasia and allied disorders. The volunteers were untrained and made the visits in the role of caring neighbours. Their purpose was to dispel apathy and to stimulate the patient's will to make the most of the faculties which remained. This common-sense approach was based on simple and ingenious methods devised by Miss Griffith which had already proved successful in two dysphasic patients. In each area the work was co-ordinated by a supervisor who also ran a weekly club for the patients.

In the opinion of the family doctors who had referred the patients the general attitude and morale of all but one of the 31 patients improved considerably, and in 21 speech had also improved. Those whose speech had not progressed developed alternative means of communication as confidence was reestablished. It seems that even when speech is irretrievably lost a reason for living and the will to make the best of what is left can be restored. In this small series neither age nor the interval since the stroke was an insurmountable obstacle to improvement-the crucial factors were strength of will and a modicum of stamina.

Miss Griffith is careful to point out that where patients showed improvement many factors were responsible, some of which were unconnected with the scheme. However, it is clear that the project has filled a serious need which is, and always will be, outside the range of the official services. Can its range be extended?

In the two areas of the pilot scheme Miss Griffith had no difficulty in finding volunteers whose perceptive approach must have been one of the main factors for success. There is no reason to believe that the tradition of voluntary service is not equally strong in the rest of the country, especially where the need is for direct contact with the individual rather than through organizations.

As the project becomes better known there is likely to be a demand for similar help in other areas. What should this project entail ? Certainly not a large bureaucratic organization; the scheme has succeeded at a local level and could never be imposed from above. Not the utilization or recruitment of trained personnel, nor the expenditure of vast sums of money. The scheme demands four essentials: the interest and involvement of sufficient volunteers, the co-operation of doctors and speech therapists, a little money, and some expert guidance. Volunteers can evidently be found; as for the second, doctors and speech therapists in the Chilterns and Oxford gave increasingly enthusiastic support to the scheme as it developed. Money is short, but area health authorities might consider a grant to cover the very small sum involved. Finally, the Chest and Heart Association, which had the imagination to sponsor this pilot scheme, might provide the necessary guidance and advice for other areas.

\section{Epidemiological Aspects of Choriocarcinoma}

One of the curious features of placental choriocarcinoma is its geographical distribution. Whereas it is rare in European and North American populations it is much more common in parts of S. E. Asia, India, and Africa. Reliable and comparable data are difficult to obtain. Authors sometimes relate the incidence to total pregnancies, sometimes to deliveries, and sometimes to necropsies. The information available for Western countries is far from adequate and that for other parts of the world is often fragmentary. Whereas in Europe and N. America it occurs in about 1 in 20000 pregnancies $^{1}$ it may be as much as 20 times more frequent in the Philippines. In a recent report from University College Hospital, Ibadan, Nigeria, ${ }^{2}$ it was found in $2.2 \%$ of all the tumours examined, making it the third commonest cancer in women after that of the cervix and breast, and 1 in 89 of all necropsies were on patients with choriocarcinoma.

Since this hospital is a well-known treatment centre for the disease it is difficult to determine just how frequently choriocarcinoma is associated with pregnancy in Nigeria, but it seems clear that the tumour is more common than in Europe. Why is choriocarcinoma seen so much more frequently in some countries than others? Different histological criteria sometimes complicate the picture, but the possibility that the high incidence in S.E. Asia might be a diagnostic artefact was excluded by a multicentre study ${ }^{3}$ in the late 1950s. The 